\title{
THE PROTEASE-RESISTANT CORE OF THE REACTION CENTRE PROTEIN OF PHOTOSYSTEM I (P700 Chl $\mathrm{C}_{\mathrm{a}}$-P1)
}

\author{
by \\ URSULA G. HINZ ${ }^{\prime \prime}$ and DAVID J. SIMPSON \\ Department of Physiology, Carlsberg Laboratory, \\ Gamle Carlsberg Vej 10, DK-2500 Copenhagen Valby \\ 1)present address: Friedrich Miescher-Institut, P.O. Box 2543, CH-4002 Basel, \\ Switzerland
}

Keywords: Chlorophyll-protein, circular dichroism, fluorescence emission, photo-oxidation, polyacrylamide gel electrophoresis

\begin{abstract}
A photosystem I (PSI) complex containing about 90-100 molecules of chlorophyll per reaction centre chlorophyll P700 was isolated by selective solubilization of stacked barley thylakoids. It had a chlorophyll $a / b$ ratio greater than 12, and a low temperature ( $77 \mathrm{~K}$ ) fluorescence emission maximum at $720 \mathrm{~nm}$, characteristic of PSI depleted of its light-harvesting antenna complex. The PSI complex remained fully active after extensive proteolysis, which had cleaved the polypeptide chains into fragments of less than $5 \mathrm{kD}$, but there was only a slight increase in the mobility of the chlorophyll-containing band during non-denaturing SDS-PAGE. Estimates of molecular weight by gel filtration showed a decrease from $650 \mathrm{kD}$ to $300 \mathrm{kD}$ as a result of protease $\mathrm{K}$ treatment. This was accompanied by the loss of between 10-30 chlorophyll molecules, depending on the type of protease used, but there were no specific changes in chlorophyll absorption bands or circular dichroism spectra. There was, however, a loss of fluorescence emission at $720 \mathrm{~nm}$ (or $698 \mathrm{~nm}$ ), which is possibly due to a small number of molecules of chlorophyll $a$ acting as a sink for excitons. Photo-oxidation of P700 under light-limiting conditions was slower after proteolysis, indicating a lower efficiency of energy transfer to the reaction centre.
\end{abstract}

\section{INTRODUCTION}

The chloroplasts of higher plants contain two different photosynthetic reaction centres (photosystem II and photosystem I) in their thylakoid membranes. Photosystem II is involved in electron transport from water to plastoquinone with the generation of molecular oxygen, and the energy comes from photons which drive charge separation in the pigment
$\mathrm{P} 680$. This pigment is probably bound between two proteins, designated D1 and D2, which together with two other chloroplast-encoded polypeptides (the $\alpha$ - and $\beta$-subunits of cytochrome $b-559$, form the photosystem II "core" complex (19). This contains only 4-6 molecules of chlorophyll $a$, and another 200240 molecules of chlorophyll $a$ and $b$ are associated with other chlorophyll-proteins (LHCII,

Abbreviations: Ca697 = chlorophyll $a$ absorbing at $697 \mathrm{~nm} ; \mathrm{CPI}=\mathrm{P} 700$ chlorophyll $a$-protein I; F698 = chlorophyll fluorescing at $698 \mathrm{~nm} ; \mathrm{F} 720=$ chlorophyll fluorescing at $720 \mathrm{~nm}$; Hepes $=\mathrm{N}$-2-(hydroxyethyl)-piperazine-N'-2ethanesulphonic acid; $\mathrm{kD}=$ kilodaltons; LHCI/II = light-harvesting chlorophyll-protein of PSI/II; PAGE = polyacrylamide gel electrophoresis; $\mathrm{PSI} / \mathrm{II}=$ photosystem I/II; SDS = sodium dodecyl sulphate; Tricine = $\mathrm{N}$-(tris-(hydroxymethyl)methyl)glycine. 
CP47, CP43, CP29, CP26 and CP24) which function as light-harvesting antennae (2).

Photosystem I accepts electrons from plastocyanin and eventually reduces $\mathrm{NADP}^{+}$, the light energy being converted into chemical energy in the form of charge separation in the pigment P700. As in photosystem II, the pigment seems to be associated with a heterodimer of two chloroplast-encoded polypeptides, with apparent molecular weights of $62-68 \mathrm{kD}$. A photochemically active complex, called CPI or $\mathrm{Chl}_{a}$ P1, can be isolated by SDS-PAGE, and contains about 92 molecules of chlorophyll $a$ for every molecule of P700. Another 120 molecules of chlorophyll $a$ and $b$ are associated with a number of polypeptides in the $20-25 \mathrm{kD}$ range, and constitute the light-harvesting chlorophyll antennae of PSI $(3,4)$.

One method to investigate the structure of chlorophyll-proteins is to subject them to proteolytic attack. This has been done with isolated LHCII, where it has been shown that trypsin cleaves the polypeptide chain in the surface-exposed hydrophilic $\mathrm{N}$ - and $\mathrm{C}$-terminal regions, leaving a contiguous hydrophobic fragment which binds practically all of the chlorophyll (12). The postulated folding pattern of the amino acid sequence deduced from the nucleotide sequence of the two photosystem I reaction centre genes (psaA and psaB) (8) contains between 10 and 12 potential membrane spanning $\alpha$-helices (9) which may be expected to bind chlorophyll $a$. We have analysed the properties of the isolated PSI core by treating it with different proteases and measuring the spectral and functional properties of the purified proteolysed product. This has involved the measurement of low temperature fluorescence emission, low temperature absorption and circular dichroism spectra, along with determination of the chlorophyll:P700 ratio and the kinetics of P700 photo-oxidation under light-limiting conditions.

\section{MATERIALS AND METHODS}

\subsection{Plant material}

Wild type barley seedlings (Hordeum vulgare cv. Svalöfs Bonus) were grown for 7 days in tap water-moistened vermiculite under continuous illumination (1700 lux) from Sylvania Gro-lux fluorescent tubes.

\subsection{Isolation of photosystem I}

We used a modification of the procedure described by Møller and Høנ (17). All steps were performed at $4{ }^{\circ} \mathrm{C}$. Pre-cooled seedling leaves were homogenized in $20 \mathrm{~mm}$-Tricine, $\mathrm{pH}$ $6.3,350 \mathrm{~mm}$-sorbitol, $5 \mathrm{~mm}-\mathrm{MgCl}_{2}$, and the slurry filtered through two layers of miracloth. The filtrate was centrifuged for $10 \mathrm{~min}$ at $5000 \times$ g. The chloroplast pellet was osmotically shocked by resuspension in $5 \mathrm{~mm}-\mathrm{MgCl}_{2}, 15$ $\mathrm{mm}-\mathrm{NaCl}, 20 \mathrm{~mm}-\mathrm{Hepes}, \mathrm{pH}$ 6.3, and the thylakoid membranes pelleted by a further centrifugation for $10 \mathrm{~min}$ at $5000 \times \mathrm{g}$. The pellet was resuspended in the same medium, incubated for $20 \mathrm{~min}$ in darkness, and centrifuged for $10 \mathrm{~min}$ at $10,000 \times \mathrm{g}$. The thylakoids were resuspended in the same medium to a final chlorophyll concentration of $2 \mathrm{mg} \cdot \mathrm{ml}^{-1}$, concentrated $(100 \%)$ Triton X-100 was added (25 mg per mg chlorophyll) and the mixture stirred for $35 \mathrm{~min}$ in the dark. Grana partition membranes enriched in photosystem II were removed by centrifugation for $30 \mathrm{~min}$ at $48,000 \times \mathrm{g}$. The PSI-enriched supernatant was applied to the top of a $10-30 \%$ sucrose gradient formed by freezethawing of $15 \%$ sucrose, $10 \mathrm{~mm}$-Tricine, $\mathrm{pH} 8.0$, $0.025 \%$ Triton $\mathrm{X}-100$, and ultracentrifuged for $24 \mathrm{~h}$ in an SW27 rotor. Free chlorophyll and soluble proteins remained on the top of the gradient, while PSI sedimented as a dark green band. The PSI fractions were collected with a Pasteur pipette and used immediately, or frozen in liquid nitrogen and stored at $-20^{\circ} \mathrm{C}$ for future use.

\subsection{Protease treatments}

When the aim was to determine the size of the smallest fragment still associated with chlorophyll after non-denaturing SDS-PAGE, $1 \mathrm{ml}$ of PSI complex in $10 \mathrm{~mm}$-Tricine, $\mathrm{pH} 8.0$ was incubated in the dark at $4{ }^{\circ} \mathrm{C}$, for 1 or $24 \mathrm{~h}$ with $0.1 \mathrm{ml}$ of the following proteases dissolved in 100 mM-Tricine, $\mathrm{pH} 8.0$ : subtilisin Carlsberg $\left(2 \mathrm{mg} \cdot \mathrm{ml}^{-1}\right)$ trypsin $\left(10 \mathrm{mg} \cdot \mathrm{ml}^{-1}\right)$ 


$$
\begin{aligned}
& \text { chymotrypsin }\left(10 \mathrm{mg} \cdot \mathrm{ml}^{-1}\right) \\
& \text { protease } \mathrm{K}\left(1 \mathrm{mg} \cdot \mathrm{ml}^{-1}\right) \\
& \text { pronase } \mathrm{E}\left(1 \mathrm{mg} \cdot \mathrm{ml}^{-1}\right)
\end{aligned}
$$

Under these conditions, only very small fragments were found after denaturing SDS-PAGE. To obtain larger fragments, $3 \mathrm{ml}$ of the PSI complex was incubated with $0.3 \mathrm{mg}$ of trypsin, chymotrypsin or Staphylococcus protease V8 for $1 \mathrm{~h}$ at $4{ }^{\circ} \mathrm{C}$. Incubation with $0.3 \mathrm{mg}$ of the non-specific proteases subtilisin, protease $\mathrm{K}$ and pronase $\mathrm{E}$ under the same conditions generated fragments less than $5 \mathrm{kD}$ in size. Prior to subsequent analyses, the protease-treated PSI was purified by sucrose gradient ultracentrifugation as described in section 2.2. The preparations contained typically about $0.07 \mathrm{mg}$ chlorophyll $\cdot \mathrm{ml}^{-1}$.

\subsection{Electrophoresis}

Non-denaturing SDS-PAGE used $1 \mathrm{~mm}$ thick slab gels containing $10 \%$ polyacrylamide, as described by MACHOLD et al. (16) (buffer system

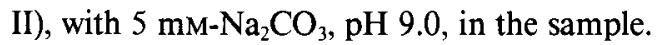
The chlorophyll-protein bands were detected by their green colour, and their position was marked before staining the gel with Coomassie brilliant blue to detect polypeptide bands not associated with chlorophyll. For denaturing SDS-PAGE, samples were first heated with $0.5 \%$ SDS, $5 \mathrm{~mm}$-dithiothreitol and $5 \mathrm{~mm}-\mathrm{Na}_{2} \mathrm{CO}_{3}$ in a boiling water bath for $5 \mathrm{~min}$, and then applied to gels containing $6 \mathrm{M}$-urea, as described by PICCIONI et al. (21), or alternatively buffer system IV with 6 M-urea of MACHOLD et al. (16). Samples for spectrophotometric measurements were isolated by non-denaturing SDS-PAGE in tube gels $(1,3)$, by loading $15 \mu$ l of PSI with a chlorophyll concentration of approximately 70 $\mu \mathrm{g} \cdot \mathrm{ml}^{-1}$.

\subsection{Spectroscopy}

Low temperature absorption spectra of polyacrylamide gel slices incubated in $60 \%$ glycerol were recorded in a liquid nitrogen-cooled Dewar vessel attached to an Aminco DW-2a spectrophotometer as described in (4). Circular dichroism and low temperature fluorescence emission spectra were recorded according to (4)

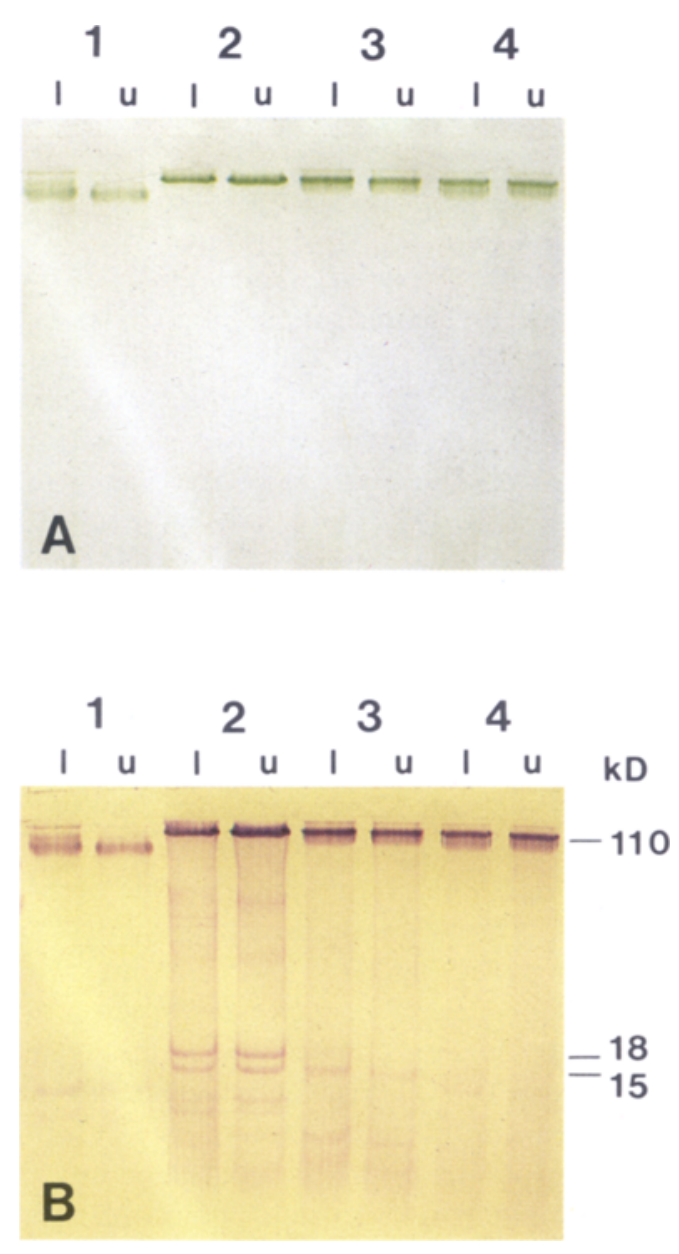

Figure 1. Non-denaturing SDS-PAGE of the purified PSI complex before and after proteolysis. The samples were incubated with the appropriate protease for $1 \mathrm{~h}(3$, 4) or $24 \mathrm{~h} \mathrm{(1),} \mathrm{re-isolated} \mathrm{by} \mathrm{ultracentrifugation}$ through a sucrose gradient, and applied directly to the gel. $100 \mu \mathrm{l}$ of material from the upper (u) or lower (l) limit of the PSI band, containing about $70 \mu \mathrm{l}$ chlorophyll $\cdot \mathrm{ml}^{-1}$ was applied to each lane. (A) Unstained gel (B) after fixation and staining with Coomassie brilliant blue.

1: PSI complex after $24 \mathrm{~h}$ digestion with trypsin.

2: untreated PSI complex.

3: PSI complex after $1 \mathrm{~h}$ digestion with subtilisin. 4: PSI complex after $1 \mathrm{~h}$ digestion with trypsin.

and (12). P700 was measured spectrophotometrically with the difference spectrum obtained from the ferricyanide-oxidized and ascorbate- 
reduced sample, or by photo-oxidation with non-saturing $550 \mathrm{~nm}$ light by dual wavelength spectroscopy $(4,14)$.

\section{RESULTS}

A functional photosystem I complex was isolated by differential solubilization of stacked thylakoids with Triton X-100, followed by sucrose gradient ultracentrifugation. After nondenaturing SDS-PAGE, a single green band (CPI) with an apparent molecular weight of 110 $\mathrm{kD}$ was seen (Fig. 1A), and staining with Coomassie blue revealed two additional polypeptides with apparent molecular weights of 15 and $18 \mathrm{kD}$ (Fig. 1B). There was occasional contamination with a $60 \mathrm{kD}$ doublet due to the $\alpha$ and $\beta$ subunits of the chloroplast coupling factor.

Digestion with different proteases for 1 or 24 h at $4{ }^{\circ} \mathrm{C}$ (see section 2.3 ), followed by non-denaturing SDS-PAGE, gave rise to chlorophyllprotein bands with electrophoretic mobilities slightly higher than CPI. The fastest migrating band had an apparent molecular weight of 95 $\mathrm{kD}$, but there were other discrete forms ranging from 98 to $106 \mathrm{kD}$ (Fig. 1a). It was not possible to increase further the mobility of the CPI band, since exposure to higher concentrations of proteases for longer incubation times caused the chlorophyll-protein band to disappear. Staining the gels with Coomassie blue showed that the 15 and $18 \mathrm{kD}$ polypeptides were the first to disappear upon treatment with proteases. When the same protease-treated samples were subjected to denaturing SDS-PAGE, no Coomassie-staining bands could be resolved, indicating that the polypeptide chains had been cleaved to fragments of less than $5 \mathrm{kD}$.

The molecular weight of the PSI complex before and after proteolysis was estimated by gel filtration using an ACA34 column equilibrated with $0.1 \%$ SDS, 100 mM-NaHCO 3 , pH 9.0, 0.5 mM-dithiothreitol. The PSI complex was stable under these conditions, as evidenced by the absence of free chlorophyll during elution. Untreated PSI co-eluted with thyroglobulin (665 $\mathrm{kD})$, very soon after the void volume. After digestion with protease $\mathrm{K}$ for $1 \mathrm{~h}$ at $4{ }^{\circ} \mathrm{C}$, the PSI complex eluted at a position corresponding to a
Table I. Photo-oxidation of P700 in protease-treated PSI-90

\begin{tabular}{|c|c|c|c|}
\hline \multirow[b]{2}{*}{ Treatment } & \multicolumn{2}{|c|}{$\begin{array}{l}\text { Molecular ratios of; } \\
\text { chlorophyll to P700; }\end{array}$} & \multirow[b]{2}{*}{$\mathfrak{t}_{1 / 2}(s)$} \\
\hline & Chemical & $\begin{array}{l}\text { Photo- } \\
\text { chemical }\end{array}$ & \\
\hline Control & 93.3 & 99.7 & 1.14 \\
\hline Staphylococcal V8 & 82.4 & 105.6 & 1.34 \\
\hline Protease $\mathrm{K}$ & 81.3 & 77.9 & 2.20 \\
\hline Subtilisin & 78.2 & 84.8 & 2.24 \\
\hline Chymotrypsin & 79.6 & 82.7 & 1.69 \\
\hline Trypsin & 77.3 & 82.1 & 2.28 \\
\hline \multicolumn{4}{|l|}{ Extended proteolysis } \\
\hline Control & 77.2 & 93.8 & 1.46 \\
\hline Staphylococcal V8 & 79.4 & 96.7 & 1.22 \\
\hline Protease K & 70.6 & 66.3 & 3.86 \\
\hline Subtilisin & 63.2 & 81.9 & 2.72 \\
\hline Trypsin & 72.8 & 76.9 & 2.52 \\
\hline Pronase $\mathrm{E}$ & 62.6 & 62.6 & 3.78 \\
\hline
\end{tabular}

molecular weight of $\approx 300 \mathrm{kD}$. When trypsinor protease K-treated PSI was re-subjected to sucrose gradient ultracentrifugation, it sedimented slightly slower than the control. Since the sedimentation depends on the lipid content and the amount of detergent bound, we did not attempt to quantitate these differences.

The functional properties of protease-treated PSI were assayed by P700 oxidation, measured both chemically and photochemically. The purified PSI contained about 90 molecules of chlorophyll per molecule of $\mathrm{P} 700$, with a molecular chlorophyll $a / b$ ratio of $12-15$. This should be compared with a molecular ratio for chlorophyll:P700 of about 100 and for chlorophyll $a / b$ of 7.6 for the initial supernatant (Table I). In general, there was a good agreement between photochemical and chemical determination of P700. Treatment of unfrozen PSI for $1 \mathrm{~h}$ with different proteases caused the loss of 10-20 molecules of chlorophyll $a$ per molecule of P700 and a slower photo-oxidation of P700, except for Staphylococcus V8 protease. Extended incubation $(24 \mathrm{~h}$ ) caused the loss of a further 0-15 molecules of chlorophyll, depending on the protease. Thus V8 and trypsin had very little effect on the loss of chlorophyll or photo-oxida- 


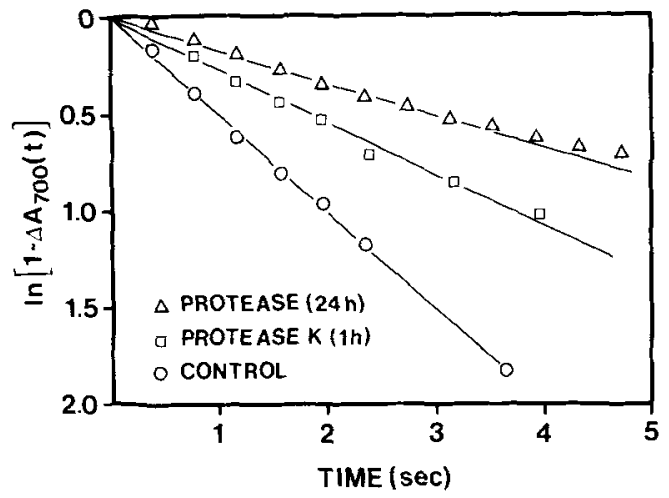

Figure 2. Logarithmic plots of the absorbance change at $700 \mathrm{~nm}$ with time, due to photo-oxidation under light-limiting conditions. The apparent rate constant $\mathrm{K}_{1}$ measures the number of photons absorbed per second by the antenna chlorophyll of PSI. It decreases from $0.50 \mathrm{~s}^{-1}$ for the untreated material, to $0.31 \mathrm{~s}^{-1}$ for PSI treated with protease $\mathrm{K}$ for $1 \mathrm{~h}$, and $0.18 \mathrm{~s}^{-1}$ after treatment with protease $\mathrm{K}$ for $24 \mathrm{~h}$.

tion kinetics, whereas a much greater loss of chlorophyll resulted after treatment with subtilisin and protease $\mathrm{K}$ (Table I and Fig. 2).

The liquid nitrogen $(77 \mathrm{~K}$ ) absorption spectra of CPI isolated from SDS-PAGE on tube gels showed little change after proteolysis of PSI (Fig. 3 ), and the fourth derivative showed only slight changes in the $670 \mathrm{~nm}$ region due to chlorophyll $a$ (Figs. $4 \mathrm{a}$ and $b$ ). The fluorescence emission spectra of protease-treated PSI were measured

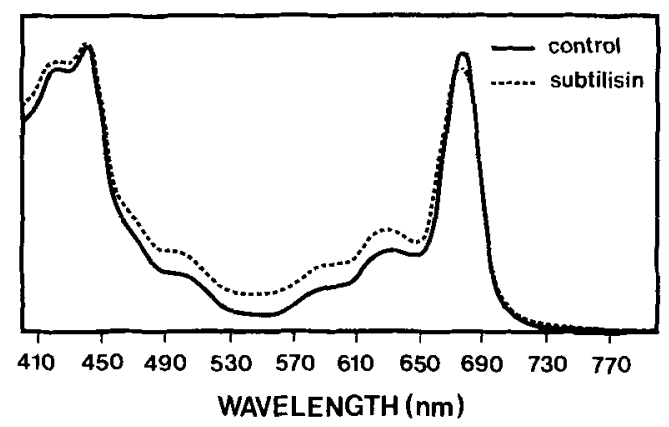

Figure 3. Low temperature absorption spectra of CPI from PSI before and after treatment with subtilisin. Three gel slices were used, with a maximum absorbance at $675-8 \mathrm{~nm}$ of about 0.5 units.
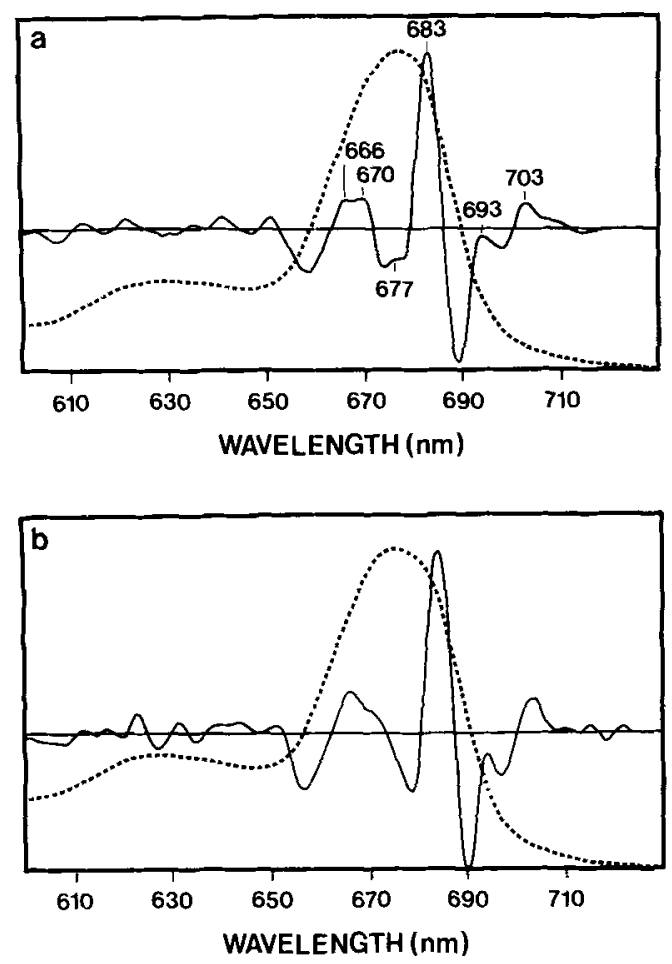

Figure 4. Fourth derivatives of the $77 \mathrm{~K}$ absorption spectra of CPI before (a) and after (b) treatment with subtilisin. There is almost no difference between the two spectra in the region due to absorbance by chlorophyll $a$.

at a temperature of $77 \mathrm{~K}$ using material taken directly from the sucrose gradient after removal of protease. The control material had an emission maximum at $720 \mathrm{~nm}$ typical of CPI uncontaminated with LHCI (Fig. 5), with another peak at $677 \mathrm{~nm}$ due to disconnected chlorophyll. Trypsin- and V8-treated PSI showed the same fluorescence emission spectra as the control, although the $677 \mathrm{~nm}$ peak was always present. After treatment with pronase $\mathrm{E}$, protease $\mathrm{K}$, or subtilisin for $1 \mathrm{~h}$, there was an almost complete loss of the $720 \mathrm{~nm}$ peak, while the $677 \mathrm{~nm}$ peak remained. Similar results were obtained with CPI isolated after non-denaturing SDS-PAGE, with untreated PSI and V8-treated PSI producing a single emission maximum at $720 \mathrm{~nm}$. CPI isolated from PSI treated with protease $\mathrm{K}$ or chymotrypsin had a fluorescence emission 


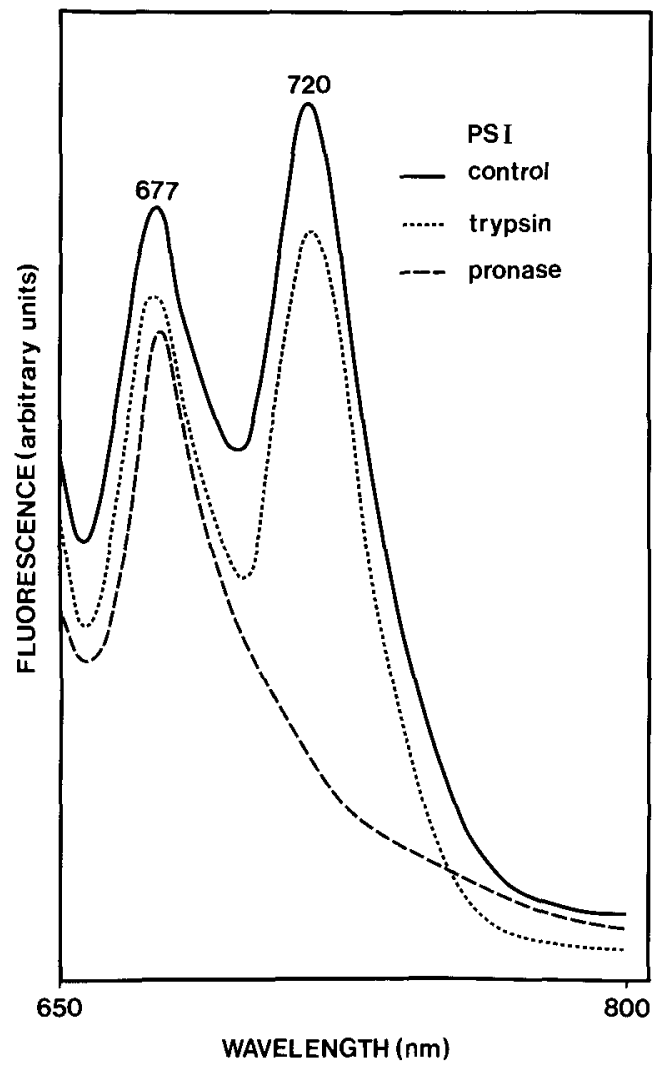

Figure 5. Low temperature fluorescence emission spectra of control and protease-treated PSI complex. Aliquots $(10 \mu \mathrm{l}$ containing about $70 \mu \mathrm{l}$ chlorophyll $\cdot \mathrm{ml}^{-1}$ ) from the second sucrose gradient were applied to filter paper discs. The amplitude of the pronase $E$ sample is $4 \times$ that of the others.

shoulder at $698 \mathrm{~nm}$ in addition to the maximum at $720 \mathrm{~nm}$. Trypsin-treated PSI gave rise to two chlorophyll-protein bands, the upper one having an emission peak at $720 \mathrm{~nm}$, while the lower band fluoresced only at $677 \mathrm{~nm}$.

The circular dichroism spectrum of the PSI preparation had the characteristic double signal in the red $(3,4)$, with a maximum at $678 \mathrm{~nm}$ and a minimum at $695 \mathrm{~nm}$ (Fig. 6). There was no negative signal at $652 \mathrm{~nm}$, indicating the absence of chlorophyll $b$, and there were positive signals in the $450-550 \mathrm{~nm}$ region due to the presence of carotenoids (cf. 22). Trypsin treatment did not cause a reduction in the amplitude of the signals in the red region, although the maximum was shifted to $685 \mathrm{~nm}$, and the signals around 500 $\mathrm{nm}$ were much reduced, indicating that the carotenoids associated with PSI and a small part of the antenna chlorophyll were disorganised or lost.

The circular dichroism spectrum in the UV region was measured before and after trypsin treatment, and showed that the secondary structure of the protein remained virtually unchanged (Fig. 7). It was not possible to detect a decrease in the proportion of $\alpha$-helix, supporting the hypothesis that the protease treatment removed water-exposed loops of the polypeptide chain (see ref. 9), but did not affect the helical transmembrane segments.

\section{DISCUSSION}

The method described here permits the isolation of large quantities of a functional PSI complex, devoid of LHCI, with a chlorophyll:P700 ratio of $90-100$ and associated with two low molecular polypeptides of about 15 and $18 \mathrm{kD}$. It corresponds to the PSI-90 complex described by BASSI and SIMPSON (1987), and similar PSI preparations from cyanobacteria (14). Variation of the solubilisation procedure and detergent concentration allows the isolation of PSI with more chlorophyll attached and a more complex polypeptide composition $(4,7$, 18,20 ).

Treatment of this PSI complex with different concentrations of proteases caused only a minor increase in the mobility of the $\mathrm{P} 700 \mathrm{Chl}_{a}$ protein 1 (CPI) after non-denaturing SDSPAGE, from $110 \mathrm{kD}$ to $95 \mathrm{kD}$. The presence of discrete chlorophyll-containing bands in this process suggests that the digestion of CPI occurs in a stepwise manner, with an initial preferential cleavage of specific bonds, allowing a subsequent cleavage of other water-exposed peptide bonds. There appears to be only one chlorophyll-binding domain, and this domain may consist of several $82-84 \mathrm{kD}$ subunits, since it was not possible to produce chlorophyll-binding fragments of less than $95 \mathrm{kD}$ apparent molecular weight. Very mild proteolysis, with low concentrations $(10-300 \mu \mathrm{g})$ of pronase per $\mathrm{mg}$ chlorophyll for $20 \mathrm{~min}(20)$, first cleaves the apoprotein of CPI to a $48 \mathrm{kD}$ fragment, which is subsequently cleaved to a $30 \mathrm{kD}$ and a $17 \mathrm{kD}$ 


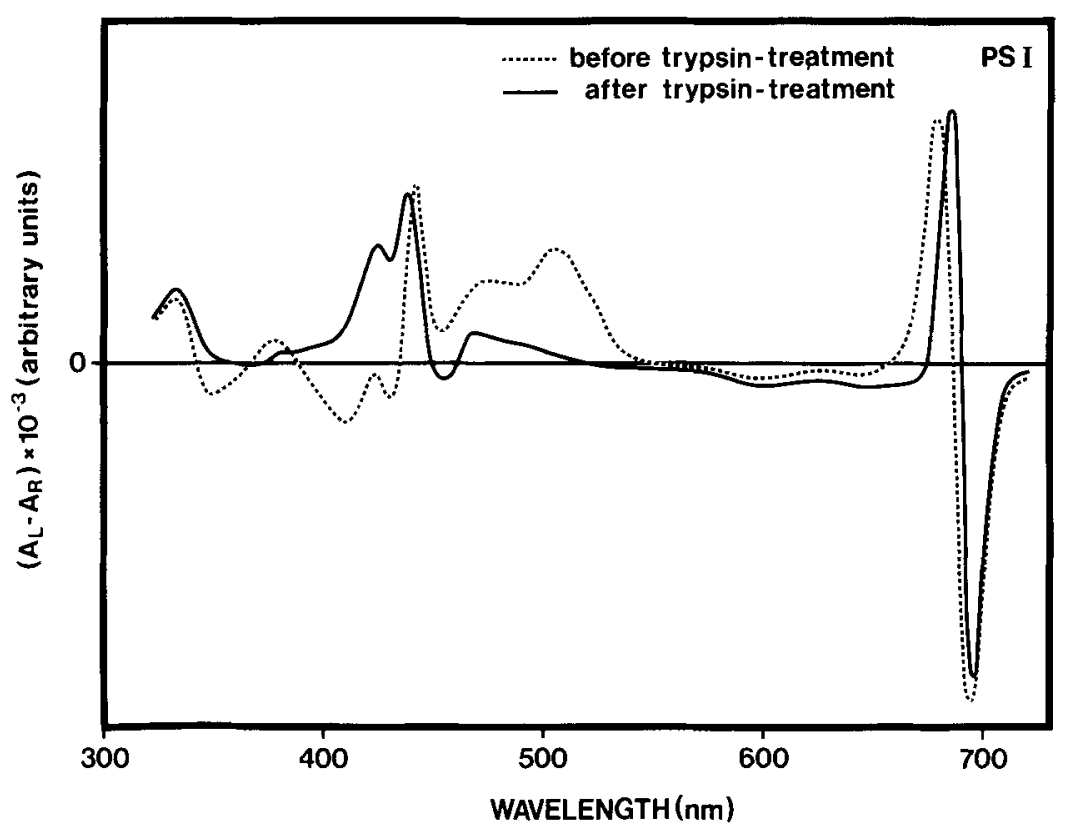

Figure 6. Room temperature circular dichroism spectra of the PSI complex before and after trypsin treatment. Chlorophyll concentration was $10 \mu \mathrm{g} \cdot \mathrm{ml}^{-1}$.

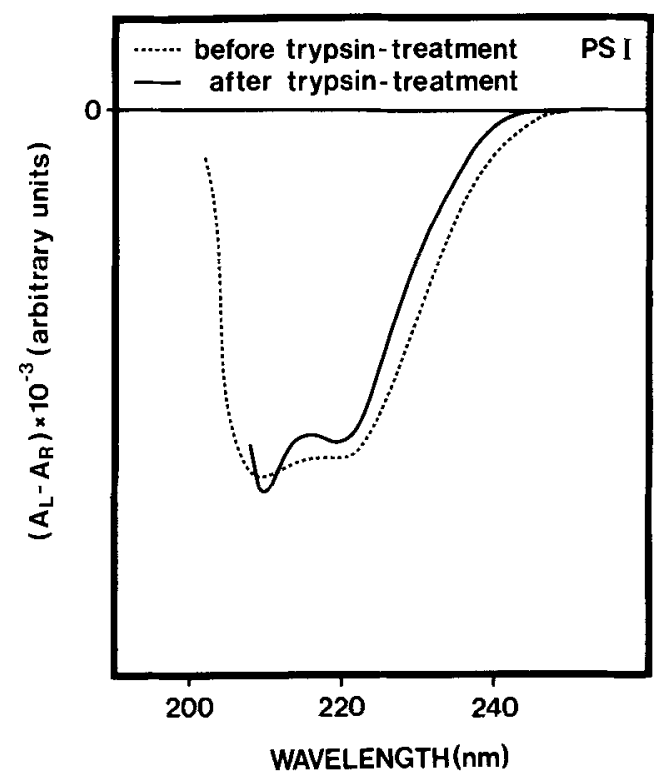

Figure 7. Room temperature circular dichroism spectra of the PSI complex in the UV range before and after trypsin treatment. fragment. This treatment, both of isolated PSI200 and intact thylakoids, did not affect the donation of electrons to P700 from plastocyanin, in contrast to trypsin, which was used in much higher amounts relative to chlorophyll (5, 23) with isolated PSI. Thus protease treatment destroys the sites that interact with peripheral proteins, but has little effect on the chlorophyllbinding domain.

Where non-denaturing SDS-PAGE indicated only a small decrease in the apparent molecular weight, as shown by increased electrophoretic mobility, denaturing SDS-PAGE revealed that extensive cleavage of the entire polypeptide chain had occurred after extensive proteolysis, resulting in fragments of $5 \mathrm{kD}$ or less. Examination of the primary sequence of the 82 and 84 $\mathrm{kD}$ polypeptides (8) shows that there are sufficient glutamate and aspartate residues, and lysine and arginine residues in the hydrophilic regions, so that even substrate-specific proteases, such as Staphylococcus V8 and trypsin, respectively, leave fragments little larger than the membrane-spanning regions.

However, the use of SDS-PAGE to estimate 
the molecular weight of chlorophyll-proteins is unreliable. Gel filtration measurements indicated a much greater decrease in the molecular weight of the PSI complex from about $650 \mathrm{kD}$ to $300 \mathrm{kD}$, as a result of attack by protease $\mathrm{K}$. This is consistent with the loss of the two small polypeptides plus about half of the mass of the 82 and $84 \mathrm{kD}$ polypeptides. Using the model of FISH et al. (9) to predict which parts of the polypeptide chain are buried in the membrane, even trypsin, attacking only at lysine and arginine residues, can remove between $41 \%$ and $50 \%$ of these polypeptides. The molecular weight of a similar PSI preparation from Phormidium laminosum was estimated by HPLC at about $600 \pm 50 \mathrm{kD}$ by BOEKEMA et al. (6). The difference between these values and lower values estimated from protein: chlorophyll ratio $(460 \mathrm{kD}$, LUNDELL et al. (14)) and SDS-PAGE (440 kD, ForD et al. (10)) may be accounted for by the amount of lipid and detergent associated with the PSI complex.

Inspite of the loss of $50 \%$ or more of the polypeptide mass, the chlorophyll: P700 measurements show that the bulk of the chlorophyll remains associated with the PSI complex. The loss of chlorophyll, which can be up to $25-30$ molecules per $\mathrm{P} 700$, is probably due to increased sensitivity of the hydrophobic core to detergent as a result of protease attack, since there is little change in the chlorophyll:P700 ratio in PSI stored in detergent at $4{ }^{\circ} \mathrm{C}$ in the absence of protease. These results are consistent with the hypothesis that all the chlorophyll is associated with the membrane-spanning $\alpha$-helices in the model of FISH et al. (9).

In comparison with proteolysis, it is possible to remove much more chlorophyll from PSI using detergent or solvent extraction, and still retain $\mathbf{P 7 0 0}$ activity, with chlorophyll:P700 ratios as low as $30(24)$ or even 7-10 (13). Thus, in the absence of detergent, the non-covalent interactions between transmembrane helices are sufficient to maintain the PSI complex in a functional state. A possible role of disulphide bonds has been indicated from the results of subtilisin digestion of intact thylakoids, where it was shown that CPI was present after SDS-PAGE but only in the absence of mercaptoethanol (15), although this was not observed by us when the isolated PSI complex was treated with subtilisin. Of the four cysteines in the $84 \mathrm{kD}$ polypeptide, two are probably associated with $\mathrm{Fe}-\mathrm{S}$ clusters, and one is buried within the membrane (9).

If, as has been hypothesised, the chlorophyll is associated with histidines, it is worth noting that there are 24 histidines conserved in the transmembrane helices of both polypeptides, and 21 of these are found in just 7 of the 11 postulated helices (9). This suggests a tetrameric structure for CPI, binding 96 molecules of chlorophyll $a$. This has already been suggested by LUNDELL et al. (14), based on the chlorophyll:P700 ratio and the protein:chlorophyll ratio $(3: 1)$ of the cyanobacterial PSI complex, and independently from the results of uniform labelling with ${ }^{14} \mathrm{C}$. Both calculations used a molecular weight of $70 \mathrm{kD}$ for the apoprotein. $\mathrm{A}$ tetrameric structure is the minimum size if $\mathrm{CPI}$ is to be able to coordinate 2 [2Fe-2S] clusters through cysteine side chains (11). However, a trimeric or hexameric structure for isolated cyanobacterial PSI has been suggested from computer-aided electron microscopy (6).

Extensive proteolysis does not destroy P700, although the kinetics of its photo-oxidation under light-limiting conditions were much slower after treatment with most of the proteases, with the notable exception of Staphylococcus V8 (Table I). This may have been due to the more specific nature of this protease, which would result in the removal of less of the hydrophilic regions between the membranespanning regions, with less disturbance to the hydrophobic core. The rate of $\mathrm{P} 700$ photo-oxidation is much slower than can be accounted for by the loss of chlorophyll alone, and is probably due to alterations in the associations between chlorophyll and the polypeptide induced by protease treatment. Similar results with protease $\mathrm{K}$ were reported by LuNDELL et al. (14), both with respect to loss of chlorophyll, and P700 oxidation kinetics. The effect of SDS on P700 photo-oxidation is even more dramatic $(4,14)$, although little chlorophyll is lost.

The spectral data (circular dichroism, absorption and fluorescence emission) provide further information about the nature of the changes in the pigments associated with CPI after proteolysis. There is a small change in the position of the 
chlorophyll $a$ doublet from 678 to $685 \mathrm{~nm}$, and a dramatic loss of signal due to disorganisation or loss of carotenoids, suggesting that the latter are accessible and therefore located peripherally. The relatively minor changes in the low temperature absorption spectra of chlorophyll $a$, with no apparent loss of any of the major absorbing chlorophyll $a$ species (Figs. 4a and b), is consistent with this interpretation. In contrast, there can be a complete loss of $720 \mathrm{~nm}$ fluorescence, even though the PSI complex retains activity. Furthermore, the fluorescence emission peak shifts first to $698 \mathrm{~nm}$ and then to $677 \mathrm{~nm}$. A 695 $\mathrm{nm}$ peak is found after detergent-induced chlorophyll loss (18).

The loss of F720 (and F698) must be associated with the loss of the 10-30 chlorophylls removed during proteolysis, but this is not revealed as a specific change in the circular dichroism or absorption spectra. It thus seems unlikely that F720 comes from a chlorophyll $a$ species absorbing at 696-697 (Ca697), as suggested by Mullet et al. (1980). Even though the chlorophyll is fluorescing at $677 \mathrm{~nm}$, it is still attached to the polypeptide and can transfer excitation energy to P700, as shown by the chlorophyll:P700 ratio and its relatively low fluorescence yield compared with free chlorophyll (Fig. 5). F720 is not an indicator of antenna connectivity, since it is found in CPI isolated by SDS-PAGE, where the rate of $\mathrm{P} 700$ photo-oxidation is extremely slow $(4,14)$. Based on the above evidence, F720 may come from a small number of chlorophyll $a$ molecules that act as a sink for excitons at $77 \mathrm{~K}$, but which is not essential for energy transfer to $\mathrm{P} 700$.

\section{ACKNOWLEDGEMENTS}

We wish to thank Professor DITER vON WETTSTEIN for his encouragement and support during the course of this work, and for critically reading the manuscript. We are grateful to ANN-SOFI STEINHOLTZ and NINA RASMUSSEN for photographic work and for drawing the figures.

\section{REFERENCES}

1. BASSI, R.: Spectral properties and polypeptide composition of the chlorophyll-proteins from thylakoids of granal and agranal chloroplasts of mays (Zea mays L.). Carlsberg Res. Commun. 50, 127143 (1985)

2. Bassi, R., G. Høyer-Hansen, R. Barbato, G.M. GIACOMETTI \& D.J. SIMPSON: Chlorophyll-proteins of the photosystem II antennae system. J. Biol. Chem. 262, 13333-13341 (1987)

3. BASSI, R., O. MACHOLD \& D.J. SIMPSON: Chlorophyll-proteins of two photosystem I preparations from maize. Carlsberg Res. Commun. 50, 145-162 (1985)

4. BASSI, R. \& D.J.SIMPSON: Chlorophyll-protein complexes of barley photosystem I. Eur. J. Biochem. 163, 221-230 (1987)

5. BhardwaJ, R., K.O. Burkey, B.C. TRIPATHY \& E.L. Gross: Effect of trypsin treatment of photosystem I particles on the electron donation to P700. Plant Physiol. 70, 424-429 (1982)

6. Boekema, E.J., J.P. Dekker, M.H. van Heel, M. Rogner, W. SAENGer, I. WitT \& H.T. WitT: Evidence for a trimeric organization of the photosystem I complex from the thermophilic cyanobacterium Synechococcus sp. FEBS Lett. 217, 283286 (1987)

7. DunahaY, T.G. \& L.A. StaEhelin: Isolation of photosystem I complexes from octyl glucoside/sodium dodecyl sulfate solubilized spinach thylakoids. Characterization and reconstitution into liposomes. Plant Physiol. 78, 606-613 (1985)

8. FISH, L.E., U. KÜCK \& L. BOGORAD: Two partially homologous adjacent light-inducible maize chloroplast polypeptides of the P700 chlorophyll a-protein complex of photosystem I. J. Biol. Chem. 260, 1413-1421 (1985a)

9. FISH, L.E., U. KÜCK \& L. BOGORAD: Analysis of the two partially homologous P700 chlorophyll a proteins of maize photosystem I: predictions based on the primary sequences and features shared by other chlorophyll proteins. In: Molecular Biology of the Photosynthetic Apparatus (Steinback, K.E., S. Bonitz, C.J. Arntzen \& L. Bogorad eds.). Publ.: Cold Spring Harbor Laboratory. pp. 111-120 (1985b)

10. Ford, R.C.,D. Picot \& R.M. Garavito: Crystallization of the photosystem I reaction centre. EMBO J. 6, 1581-1587 (1987)

11. GOLDBECK, J.H., A.E. MCDERMOTT, W.K. JONES \& D.M. KURTZ: Evidence for the existence of [2Fe$2 \mathrm{~S}$ ] as well as [4Fe-4S] clusters among $F_{A}, F_{B}$ and $F_{x}$. Implications for the structure of the photosystem I reaction center. Biochim. Biophys. Acta 891, 94-98 (1987) 
12. Hinz, U. \& K.G. WeLINDER: The light-harvesting complex of photosystem II in barley. Structure and chlorophyll organization. Carlsberg Res. Commun. 52, 39-54 (1987)

13. IKEGAMI, I. \& S. ITOH: Chlorophyll organization in $\mathrm{P}-700$-enriched particles isolated from spinach chloroplasts. CD and absorption spectroscopy. Biochim. Biophys. Acta 851, 75-85 (1986)

14. Lundell, D.J., A.N. Glazer, A. Melis \& R. MalkIN: Characterization of a cyanobacterial photosystem I complex. J. Biol. Chem. 260, 646-654 (1985)

15. Machold, O., D.J. Simpson \& G. Høyer-HANSEN: Correlation between the freeze-fracture appearance and polypeptide composition of thylakoid membranes in barley. Carlsberg Res. Commun. 42, 499-516 (1977)

16. Machold, O., D.J. Simpson \& B.L. Møller: Chlorophyll-proteins of thylakoids from wild type and mutants of barley (Hordeum vulgare). Carlsberg Res. Commun. 44, 235-254 (1979)

17. MølLeR, B.L. \& P.B. HøJ: A thylakoid polypeptide involved in the reconstitution of photosynthetic oxygen evolution. Carlsberg Res. Commun. 48, 161-185 (1983)

18. Mullet, J.E., J.J. Burke \& C.J. ARnTzen: Chlorophyll-proteins of photosystem I. Plant Physiol. 65, 814-822 (1980)

19. NAMBA, O. \& SATOH K.: Isolation of a photosystem
II reaction center consisting of D1 and D2 polypeptides and cytochrome b-559. Proc. Natl. Acad. Sci. USA 84, 109-112 (1987)

20. Ortiz, W., E. Lam, S. Chollar, D. Munt \& R. MALKIN: Topography of the protein complexes of the chloroplast thylakoid membrane. Studies of photosystem I using a chemical probe and proteolytic digestion. Plant Physiol. 77, 389-397 (1985)

21. Piccioni,R.G.,P. BenNoun \& N.-H. Chua: A nuclear mutant of Chlamydomonas reinhardtii defective in photosynthetic photophosphorylation. Characterisation of the algal coupling factor ATPase. Eur. J. Biochem. 117, 93-102 (1981)

22. RaWyler, A., L.E.A. HenRY \& P.A. SiegenthaleR: Acyl and pigment lipid composition of two chlorophyll-proteins. Carlsberg Res. Commun. 45, 443$451(1980)$

23. Takabe, $T$, $H$. IshikaWa \& $S$. Kubo: Effects of trypsin treatment on the photochemical activity and polypeptide composition of the P700-chlorophyll a protein complex. Agric. Biol. Chem. 50, 1131-1137 (1986)

24. TAKabe, T., H. ISHIKaWA, S. Niwa \& S. ITOH: Electron transfer between plastocyanin and $P 700$ in highlypurified photosystem I reaction center complex. Effects of $\mathrm{pH}$, cations and subunit peptide composition. J. Biochem. (Tokyo) 94, 1901-1911 (1983)

Accepted by H. KLENOW 